\title{
Frank Voehl and H. James Harrington: Change Management-Manage the Change or It Will Manage You
}

\author{
Ken Jones ${ }^{1}$
}

(C) Springer-Verlag Berlin Heidelberg 2016

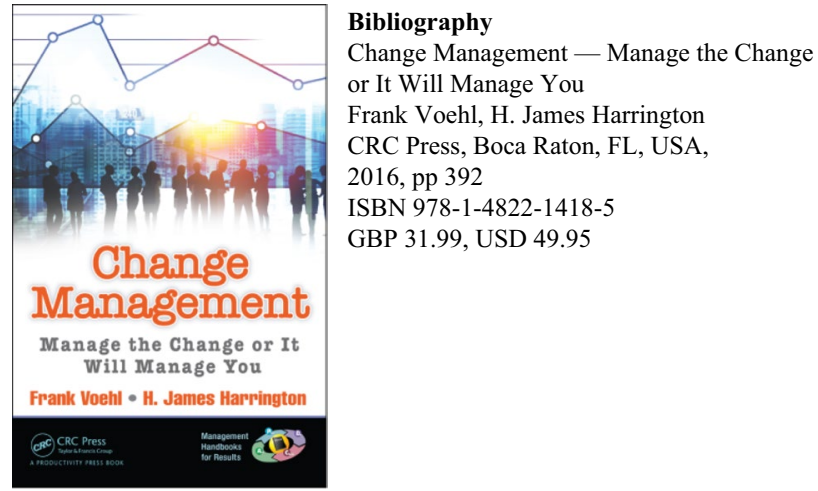

When first received, this book appeared to have little in common with any scientific discipline; until one considered the massive changes that have taken place in the chemical industry over the last two decades. The title says it all. Read the main title backwards or forwards, followed by the subtitle. It rapidly becomes clear that the principles are universal. The expected audience is senior management (this is number six in a management series), but more ambitious lower management levels will gain much if they wish to enhance their prospects by familiarisation of a process often missing at all levels of management.

The 'Management Change' concept is a modern version of Bloom's 'Taxonomy for Learning Organisations' as applied to management, where levels of intellectual behaviour were classified into knowledge, comprehension, application, analysis, evaluation and synthesis. The authors have re-edited Bloom's categories into a more modern five sections; remembering, understanding, applying, analysing/

Ken Jones

chromatographia@springer.com

1 Knutsford, Cheshire, UK evaluating, and creating, totalling sixteen chapters. So far this is pure psychology, not science, although most psychologists would argue quite vehemently that it is a science. At this juncture perhaps it might be worth recalling Nietzsche's dwarf (the academic scholar), when standing on the shoulders of Zarathustra, fails to understand the profundity of the vision offered to him.

The best managers instinctively know that the change management system works through three management systems; quality, project and daily work management, with an objective of altering the work method to improve the overall process. For many managers no thought is required. They will automatically make all necessary changes to address the perceived shortcomings, with or without higher level permission. Equally often, others will be happy with the status quo; and so the system within their aegis will stultify and ultimately die. It then follows that the most successful organisations are those that embed change from top to bottom, allowing line managers sufficient flexibility to make change at their own level. A hands-on guide for behavioral change, "The Change Management Pocket Guide" (Nelson and Aaron), is indicated as a quick way into the overall process.

It is gratifying to note a whole chapter in this book is devoted to the assessment of risk. Poor judgment (or total ignorance) of this major factor, often the primary cause of the spectacular collapse of individuals, companies and even countries, far exceeds the second-most common factor of inadequate cash-flow. 